\title{
Vernacular: Its Features, Relativity, Functions and Social Significance
}

\author{
Li Ming \\ School of Interpreting and Translation Studies, Institute of Hermeneutics, Center for Translation Studies, Guangdong University of Foreign \\ Studies, Guangzhou, China
}

Email address:

drliming@126.com

\section{To cite this article:}

Li Ming. Vernacular: Its Features, Relativity, Functions and Social Significance. International Journal of Literature and Arts. Special Issue: Humanity and Science: China's Intercultural Communication with the Outside World in the New Era. Vol. 8, No. 2, 2020 , pp. 81-86. doi: 10.11648/j.ijla.20200802.17

Received: February 27, 2020; Accepted: March 16, 2020; Published: March 31, 2020

\begin{abstract}
In daily communication, people use different language varieties when contacting each other depending on different social contexts determined by factors such as participants, the setting and the topic. The use of different language varieties bears different functions or social significance. Generally, the more formal the language between participants is, the more distant their relationship; the more informal the language between participants is, the more intimate their relationship. Usually, people in the same region communicate with each other in regional dialects; people from the same social stratum or class communicate with each other in social dialects; people who are well-educated or distant in relationship or who do not share the same language or culture communicate with each other in standard language; and people from the same community or region, who are intimate to each other or who share one language or one culture communicate with each other in vernacular language. In nearly every speech community, there exists a certain vernacular language. Vernacular language is indigenous, native or local, spoken either by a rural or urban speech community, or by a lower social class; it is informal, or casual, or the least standardized; it is contrastively used with standard language; it is uncodified, but when there is a need, it is codified through the use of the dominant language, i.e., usually the standard language; its existence relies heavily on the dominant language; it is usually acquired as a first variety in the home; it is featured by colloquialisms, vulgarisms, substandard forms, and slang. There are hundreds of vernacular languages throughout the world, there. Vernacular languages, often used for a relatively narrow range of informal functions, include ethnic or tribal languages which are usually the first languages learned by people from those ethnic or tribal groups. The most typical example of vernacular language is Black English Vernacular in America. Vernacular language is even used by some writers in their literary works - Mark Twain in his The Adventures of Huckleberry Finn and Dante in his Divine Comedy. Vernacular language may become a standard language if standard language becomes outdated or is abandoned by the public. It is indispensable in daily communication as it is complementary to standard language. It can never be regarded as sub-standard or inadequate, however, as it is an important language variety.
\end{abstract}

Keywords: Vernacular, Language Variety, Society, Speech Community, Function

\section{Introduction}

Sociolinguistics is the study of language in relation to society [1]. Among its many topics on language which are related to society, vernacular is one in which sociolinguists show great interest. Language is a code. Vernacular is also a code. Every human community or society must possess a code of this kind or that or even more than one code so that people can employ the code (s) to communicate with each other. Yet the situations are extremely complex in different speech communities $^{(1)}$. For example, one speech community does not necessarily have only one code and people do not always use the same code either to address each other. People may use different codes according to different social contexts which are determined by such factors as who they speak to, where they speak and what they talk about. The different codes they employ are called language varieties. Language varieties emerge when languages are considered as social institutions which are related to their speech communities. Their emergence may be due to geographical reasons, or political 
reasons, or social reasons, or cultural reasons, or practical reasons, or some of these reasons. Within one speech community, usually there are at least these language varieties: regional dialects and social dialects, standard language and vernacular language, formal style language and informal style language. Internationally speaking, language varieties are more varied, as will be shown in Section Five of this paper.

Which language variety is used in social communication depends on these factors: the participants, the setting and the topic. But the use of different language varieties bears different functions or social significance. Generally, the more formal the language used between participants is, the more distant their relationship; the more informal the language used between participants is, the more intimate their relationship. Usually, people in the same region communicate with each other in regional dialects; people from the same social stratum or class communicate with each other in social dialects; people who are well-educated or distant in relationship or who do not share the same language or culture communicate with each other in standard language; and people from the same community or region, who are intimate to each other or who share one language or one culture communicate with each other in non-standard language, i.e., vernacular language. Nearly in every speech community, there exists a certain vernacular language. Then, what does vernacular language mean to us? What are its features and functions? What is its social significance? When, how and why vernacular language is used? The present paper aims at offering a brief survey of all these aspects.

\section{Vernacular Language: Its Definitions and Features}

The word vernacular came into the English language in the 1600 's from Latin vernaculus. It meant "domestic, indigenous, or native". In Latin, a verna was a home-born slave, or a native. To know the etymology of this word may help us a little in understanding the sociolinguistic term vernacular. This term is actually very broad in meaning and it can be used in a number of ways. And different sociolinguists have different interpretations about this term because they may emphasize one or the other of the characteristics of vernacular language. Let's see all these definitions: (1) According to Crystal [2], vernacular is "the indigenous language or dialect of a speech community". (2) The term vernacular may be used "non-technically to refer to the current local language of a region as opposed to, e.g., classical or liturgical languages, or more generally to 'popular usage' of an informal, not to say uneducated, kind. It has been used in the field to refer to the most casual style of speech produced by speakers, or, more specifically, by the least standardized speakers" [3]. (3) Vernacular usually "occur [s] in the everyday language of a place and is regarded as native or natural to it. The term is used contrastively to compare the mainly or only oral expression of a people, a rural or urban community, or a lower social class with languages and styles that are classical, literary, liturgical, or more socially and linguistically cultivated and prestigious" [4]. (4) The term vernacular "generally refers to a language which has not been standardized and which does not have official status" [5]. (5) Vernacular is "a language which is the mother tongue of a group which is socially or politically dominated by another group speaking a different language. We do not consider the language of a minority in one country as a vernacular if it is an official language in another country" [6].

From the above-cited definitions, we can see that different sociolinguists have different interpretations of vernacular language, only with one feature or the other being emphasized. Crystal emphasizes its indigenousness; Malmkjaer emphasizes its localness, informality, casualness and least standardizedness; McArthur emphasizes its nativeness, naturalness and oralness; Holmes emphasizes its non-standardizedness and non-officialness; and Fishman emphasizes that it is the mother tongue of a group. These definitions provide us with an encyclopedic view of what a vernacular language or a vernacular is. A careful analysis can demonstrate that it at least has the following characteristics:

(1) Vernacular is the mother tongue of a certain group, or to be more exact, a language variety; (2) It is indigenous, native or local, spoken either by a rural or urban speech community, or by a lower social class; (3) It is informal, or casual, or the least standardized; (4) It is contrastively used with languages or styles which have a history, a literary status, a status on formal occasions, i.e. standard languages, which are accepted by the society and linguists and which have public or overt prestige; (5) It is uncodified; it is usually only a language folk variety which does not have official status; (6) In reality, and from my observation, since vernacular is usually uncodified, if it is to be recorded, the dominant language (usually the standard language) must be employed. Therefore, its existence relies heavily on the dominant language; (7) Vernacular is usually acquired as a first variety in the home; (8) Vernacular is used for relatively circumscribed functions; (9) Vernacular is said to be featured by colloquialisms, vulgarisms, substandard forms, and slang [7].

\section{Instances of Vernacular Language}

Throughout the world, there are hundreds of vernacular languages. Even within one country, there are likely to be more vernaculars than what people can imagine. In the former Soviet Union, for example, about a hundred vernaculars were spoken there. In Papua New Guinea, there are over 700 different vernaculars, of which Buang is a typical instance. Many of these vernaculars have never been written down or described. In a multilingual speech community, many different groups may use many different ethnic or tribal languages. And these different ethnic or tribal languages are referred to as vernacular languages. Vernaculars are usually the first languages learned by people in these multilingual communities, and they are often used for a relatively narrow range of informal functions.

A very typical example is Black English Vernacular 
$(\mathrm{BEV})^{(2)}$ in America. BEV is considered as a variety of nonstandard English spoken by lower-class black people in American urban communities. To know better the concept of "vernacular", we need to elaborate on the features of BEV. Among some of its distinctive features are:

(1) the lack of a final $-s$ in the third person singular present tense, e.g.:

\section{She walk_ to school every day.}

Derrick do n't know nothing.

(2) the absence of forms of be when used as a linking verb, e.g.:

They'll probably say that they _ the boss.

If we _ fighting and we _ getting beat...

(3) the use of be to mark habitual meaning, e.g.: Sometime they be walking round here.

(4) the use of stressed "been" to indicate a remote past and unstressed "been" to indicate simply a prior state of affairs, but not necessarily one that was initiated remotely prior, e.g.:

They been called the cops, and they're still not here. (meaning: They called the cops a long time ago; they've had plenty of time to get here.)

I been had it there for years. ("been" unstressed, meaning: I have kept it there for years.)

(5) the use of "done" to mark the completion of an action, e.g.:

I done forgot to turn off the stove. (meaning: I have forgotten to turn off the stove.)

(6) the use of "be done" to indicate the future completion of an action, e.g.:

We be done washed all the cars by the time JoJo gets back with the cigarettes.

I'll be done killed him if he tries to lay a hand on my kid again.

(7) the use of "steady + v-ing" construction to indicate intensive continuation, e.g.:

Your mind is steady workin. (meaning: You are thinking continuously and intently.)

(8) the use of "come + v-ing" construction to express indignation about the action being spoken about, e.g.:

She come going in my room - didn't knock or nothing.

(Meaning: She had the nerve to go into my room without knocking.)

And these are only some of the features of BEV, there are many more. The linguistic origins of BEV are controversial. According to one view, BEV originates from the creole English used by the first blacks in America, now much influenced by contact with Standard English. An alternative view argues that BEV features can also be found in white dialects (especially those in the south), suggesting an origin in white English; the variety then became distinctive when blacks moved north to the cities, and found their southern features perceived as a marker of ethnic identity.

In literary circles, some writers also use vernacular language in their works. Mark Twain, the American writer, wrote his famous novel The Adventures of Huckleberry Finn (1884) in vernacular language, which has well depicted the local color or flavor of the place where the story took place. And it is this vernacular language that partly wins Mark Twain as a writer of realism and that paves the way to his literary success. Another typical example is Dante. This literary figure used the vernacular, i.e., the Italic dialect of Tuscany, for his masterpieces, one of which is Divine Comedy. At the outset of the fourteenth century, he speaks of his rejection of Latin for his Divine Comedy as due to his desire to obtain a wider audience, including women, who could only be reached through the vernacular [7].

\section{The Relativity of Vernacular Language}

A vernacular may exist in a relative way, however. By this, I mean that vernacular language is likely to change its role and to become a standard language while the originally standard language becomes outdated or is abandoned by the public. This interchangeability may result from the following reasons. Firstly, the definition given by sociolinguists may impose a certain language as a vernacular. For example, some sociolinguists believe that the dominant language in one country may become vernacular in another. They define vernacular as any language which is not the official language of a country [5], which, though, is not approved by Fishman. A case in point is an influential 1951 UNESCO report. It defined a vernacular language as the first language of a group socially or politically dominated by a group with a different language (ibid). In this case, in countries such as the United States where English is the language of the dominant group, a language like Spanish is referred to as a Chicano child's vernacular. But Spanish would not be regarded as a vernacular in Spain, Uruguay or Chile, where it is an official language. In this sense Greek is a vernacular language in Australia and New Zealand, but not in Greece or Cyprus. The term vernacular simply means a language which is not an official language in a particular context. This kind of vernacular can be considered as an artificially imposed one.

Secondly, as is known to all, vernaculars lack formalized grammars and lexicons and are therefore generally accorded less prestige than either standard language or classical language. However, a vernacular may become a standard language through the codification and acceptance of its grammar and lexicon [6]. Historically speaking, the literary languages of Europe now, such as French, Spanish, Portuguese, etc., originated in most cases as vernaculars in relation to Latin. But several centuries' development through the formalization of their grammars and lexicons, and the codification and acceptance of their grammars and lexicons enabled them to gain more prominence over Latin and naturally usurp the throne held by the ancient tongues including Greek, and to be elevated to be languages which possess literary, political, economic and social status. Isn't it fanciful that the two ancient Classical languages - Latin and Greek - have led to their downfall as international tongues of cultural exchange and diplomacy! In a multilingual area especially, a particular vernacular is more likely to develop the role of a language of wider communication. This kind of 
vernacular language can be treated as a naturally and historically formed one.

Sometimes a vernacular may be elevated to become a language of status because of political reasons, though, more often than not, "the struggle among different language groups to achieve pre-eminence or recognition of their own language may even cause riots and civil strife" [8]. A well-known case in point is the Indian subcontinent. In emerging from British rule, the subcontinent initially was torn by a rift between several competing vernaculars, primarily between Indo-European Hindi, spoken mostly by Hindus, and the more arabized Urdu, favored by Moslems; subsequently, after the establishment of separate nation-states, the officially recognized status of Hindi in India was challenged by a number of regional and local languages (such as Telugu in Madras and Kanarese in Bombay), a challenge which invariably implied a political test of national unity [9].

From all these, it can be concluded that usually it is only relatively speaking that a certain language variety is a vernacular.

\section{The Functions and Social Significance of Vernacular Language}

Vernacular is usually an uncodified or unstandardized language variety. It is often used in speech between people who share attitudes and values, and who may belong to the same ethnic group [5], and it is manifested by the most colloquial variety in a person's linguistic repertoire. And, as illustrated above, vernacular is contrasted with standard language. And to illustrate better the functions of vernacular, surely it is better to make a contrastive study of the functions of both standard language and vernacular language. Standard language and vernacular language are usually two distinct varieties of the same language. These two varieties often exist at the same time in a speech community. But they play different roles in social intercourse. Sociolinguists regard the former as a high (or H) variety and the latter a low (or L) variety. Correspondingly, the former serves the high functions (i.e., it is used in such formal settings as law courts, the House of Assembly or Parliament, a school, a graduation ceremony, or a retirement dinner etc.) and the latter the low functions (i.e., it is used in informal or relaxed casual contexts such as the playground and the home) in speech communities. People often use vernaculars when they communicate with their friends or with their peers. They use this kind of language variety either to reinforce the solidarity or the unification of the community itself, or to express affective meaning, or to assert their separation from outside neighbors. In other words, when two people talk to each other in vernacular language, we may infer at least the following things: (1) They may be from the same ethnic or tribal group; (2) They are communicating on an informal occasion; (3) They are familiar with each other, or may be close friends or peers; (4) They are on guard not to be intruded by people from beyond their own ethnic or tribal group. (5) They are showing intimacy towards each other or reinforcing their solidarity.

It seems that vernacular language does not play a major role in communication. But actually it does. Its existence is of great necessity and significance. Standard languages and vernacular languages are complementary to each other. And thus the vital importance of vernacular language can never be ignored. Perhaps the following situation can best illustrate the relationship between standard language and vernacular language and also the important functions of vernacular language. In Paraguay, a majority of the population came to be bilingual in both Spanish and the aboriginal language Guaraní, which only has the status of being a vernacular. Spanish is the official language and the language of education, but Guaraní is widely used for informal communication especially in rural areas, and among speakers with little formal education. Although Guaraní is often referred to as a boorish and uncultured form of speech, it has maintained itself and has even produced a literature. These may be shown in the following elaboration by Rubin [10]:

The large majority of rural Paraguayans have Guaraní as their first language and are first exposed to Spanish in the classroom. Whereas one could live in the rural areas today without ever speaking Spanish, lack of knowledge of Guaraní would be a real handicap. Although the reverse is true for the major cities, there are numerous occasions when lack of knowledge of Guaraní would isolate a person from casual speech - for example, at even the most formal dinners after-dinner jokes are usually told in Guaraní.

As to its social significance, we know that "different languages and language varieties are not only identified but they are often associated with deep-rooted emotional responses in which thoughts, feelings, stereotypes, and prejudices about people, social, ethnic and religious groupings, and political entities are strongly associated with different languages or varieties of a language [8]. Usually, people speak vernacular language just because they want to show their ethnic or social identity or to reinforce their solidarity or to express affective meaning as mentioned above. Also, as is often the case, due to the fact that vernacular language displays a much wider range of allophonic or phonologically conditioned variation than do standard languages [11], people are more likely to use these features of vernacular language to add color to their speech in their communication. What's more, people may also use vernacular language to show their prejudices against a certain group. A typical example is that in Berlin, people use vernacular language just to symbolize solidarity against the power structures, everyday culture against the dominant culture, and loyalty of the workers to themselves rather than to a class of functionaries [12].

\section{The Differences Between Vernacular Language and Other Language Varieties}

Language varieties can first be classified from an international standpoint. The differences between them are 
manifested in Fishman's [6] definitions of the terms with the senses indicated:

(1) Indigenous language. The language of the people considered to be the original inhabitants of an area. (2) Lingua franca. A language which is used habitually by people whose mother tongues are different in order to facilitate communication between them. (3) Mother or native tongue. The language which a person acquires in early years and which normally becomes his natural instrument of thought and communication. (4) National language. The language of a political, social or cultural entity. (5) Official language. A language used in the business of government - legislative, executive and judicial. (6) Pidgin. A language which has arisen as the result of contact between peoples of different languages, usually formed from a mixing of the languages. (7) Regional language. A language which is used as a medium of communication between peoples living within a certain area who have different mother tongues. (8) Second language. The language acquired by a person in addition to his mother tongue (9) Vernacular language. A language which is the mother tongue of a group, which is socially or politically dominated by another group speaking a different language. We do not consider the language of a minority in one country as a vernacular if it is an official language in another country. (10) World language $^{(3)}$. A language used over wide areas of the world.

We may also analyze language varieties from the following four socio-historical attributes:

Historicity (I), i.e., whether or not the language is the result of a process of development through use. What makes a language obviously historical is its association with some national or ethnic tradition.

Standardization (II), i.e., whether or not there exists for the language a codified set of grammatical and lexical norms which are formally accepted and learnt by the language users...

Vitality (III), i.e., whether or not the language has an existing community of native speakers...

Homogenicity (IV), i.e., whether or not the language's basic lexicon and basic grammatical structure both derive from the same pre-stages of the language.

With these four characteristics Stewart has been able to define seven language types as in the following table:

Table 1. Stewart's classification of language types.

Attributes Language Type

I II III IV type symbol

\begin{tabular}{llllll}
\hline+ & + & + & + & Standard & $\mathrm{S}$ \\
+ & + & - & + & Classical & $\mathrm{C}$ \\
+ & - & + & + & Vernacular & $\mathrm{V}$ \\
+ & - & + & - & Creole & $\mathrm{K}$ \\
+ & - & - & - & Pidgin & $\mathrm{P}$ \\
- & + & - & + & Artificial & $\mathrm{A}$ \\
& & - & - & & $\mathrm{M}$ \\
\hline
\end{tabular}

A standard language (S), such as English or French spoken by educated native speakers, has all four attributes. A classical language (C), such as Latin or Classical Arabic, has three but lacks the attribute of 'vitality'. A vernacular (V), for example, tribal languages of America or Africa, has three, but lacks the formal standardization of grammar and lexicon. A wide definition of vernacular can include dialects. Creoles $(\mathrm{K})$ and pidgin (P) languages are 'the result of the development of a secondary language for wider communication in ... contact situations where grammatical and lexical material from different sources became fused' [13]. A pidgin is only used as a second language. Its only defining feature is historicity. If it becomes a native language it develops into a creole. Esperanto is an example of an artificial language (A). Marginal languages (M) describe household languages or codes, developed among small groups.

One more language variety is dialect. The study of vernacular language is not thorough without a mention of dialect. Dialect is a language variety in which the use of grammar and vocabulary identifies the regional or social background of the user [2]. And according to Fishman [6], dialect may be subsumed under both standard languages and vernacular languages as one of the structurally identifiable subsystems. It may correlate with differences between speakers, or with differences in use for particular situations. In these cases, dialects need not normally be treated independently from the standard languages and vernacular languages of which they form a part.

From the above comparison, we can know very well the features and the differences between vernacular language and other language varieties.

\section{Conclusion}

From what has been discussed above, we can see that vernacular is a very important language phenomenon in social reality. Linguists claim that all language varieties are equal: there is no significant difference in the complexity of their linguistic structure; they all have resources for creating new vocabulary as it is needed, and for developing the grammatical constructions their speakers require. Any variety can be developed for use in any situation. A language used by a tribe buried in the mountains of Papua New Guinea or the depth of the Amazonian rain forests has the potential for use at the nuclear physics conferences of the Western world, or in the most sensitive diplomatic negotiations between warring nations. There are no differences of linguistic form between varieties which would prevent them from developing the language required for such purposes. The barriers are social and cultural [5]. Therefore, vernacular language should by no means be regarded as sub-standard or deviant or inadequate. Any study of language in relation to society should not be carried on without giving an important place to vernacular language.

Notes:

1. According to Gumperz [14] and Stern [8], a speech community is defined as a group of people (face-to-face group, gang, region, nation) who regularly communicate 
with each other, without consideration of whether the group is large or small, and whether the medium of communication they use is one language or dialect, or several dialects, codes, or languages.

2. It can also be termed Vernacular Black English (VBE) [15] or Black Vernacular English (BVE) [16]. The fact that the same concept is termed in different ways indicates that as regards which aspect (s) should be emphasized, sociolinguists have different points of view.

3. The term "world language" is now more often called "international language".

\section{References}

[1] Hudson, R. A. (1980). Sociolinguistics. Cambridge: Cambridge University Press, p. 1.

[2] Crystal, D. (1992). An Encyclopedic Dictionary of Language and Languages. Oxford: Blackwell Publishers, p. 410; p. 101.

[3] Malmkjaer, K. (ed.) (1991). The Linguistics Encyclopedia. London and New York: Routledge, p. 95.

[4] McArthur, T. (ed.) (1992). The Oxford Companion to the English Language. Oxford: Oxford University Press, p. 1086.

[5] Holmes, J. (1992). An Introduction to Sociolinguistics. London: Longman Group UK Limited, p. 80; p. 80; pp. 377-78; p. 207.

[6] Fishman, J. A. (ed.) (1968). Readings in the Sociology of Language. The Hague: Mouton Publishers, p. 689; p. 538; p. $689 ;$ p. 539.

[7] Pei, M. (1965). The Story of Language. New York: Nal Penguin Inc., p. $181 ;$ p. 348.
[8] Stern, H. H. (1983). Fundamental Concepts of Language Teaching. Oxford: Oxford University Press, p. 230; p. 237.

[9] Dallmayr, F. (1994). Language and Politics. London: University of Notre Dame Press, p. 4.

[10] Rubin, J. (1968). "Language and education in Paraguay" in Fishman, J. A., Ferguson, C. A. and Das Gupta, J. (eds.) 1968. Language Problems of Developing Nations. New York: Wiley, p. 477.

[11] Milroy, J. "Probing under the tip of the iceberg: phonological 'normalization' and the shape of speech communities" in Romaine, S. (ed.) (1982). Sociolinguistic Variation in Speech Communities. London: Edward Arnold (Publishers) Ltd., p. 39.

[12] Dittmar, N. et al. "The social significance of the Berlin vernacular" in Dittmar, N. \& Schlobinski (eds.) (1988). The Sociolinguistics of Urban Vernaculars: Case Studies and Their Evaluation. Berlin/Boston: Walter de Gruyter GmbH., p. 43.

[13] Stewart, W. A. (1962). "An outline of linguistic typology for describing multilingualism" in Rice, F. A. (ed.) 1962. Study of the Role of Second Languages in Asia, Africa, and Latin America. Washington, D. C.: Center for Applied Linguistics, pp. 19-20.

[14] Gumperz, J. J. (1968/1977). "The speech community” in Sills, D. L. (ed.) 1977. Interactional Encyclopedia of the Social Sciences. 8 vols. New York: Free Press. 381-6.

[15] Fasold, R. (1990). The Sociolinguistics of Language. Oxford: Blackwell Publishers, p. 207.

[16] Salzmann, Z. (1993). Language, Culture and Society, An Introduction to Linguistic Anthropology. Colorado: Westview Press Inc., p. 271. 